\title{
Bens públicos e recursos de acesso comum: instituições que influenciam sua conservação nos bairros Cota do Parque Estadual da Serra do Mar de São Paulo
}

\author{
Roberta Buendia Sabbagh \\ Fundação Getulio Vargas - EAESP
}

\begin{abstract}
Este artigo visa abordar o embate do uso e da conservação dos recursos naturais e de acesso comum, principalmente remanescentes florestais em áreas protegidas. $\mathrm{O}$ uso e o manejo desses recursos são temas de diversas teorias, sendo apresentados neste artigo os teóricos Garrett Hardin e Elinor Ostrom. Numa visão antagônica, Garrett Hardin aborda a problemática da coletividade no uso dos recursos, apontando a necessidade de um controle externo para evitar a superexploração, e Elinor Ostrom vê a possibilidade da autonomia da comunidade para o uso sustentável. São contrapontos entre a indução do comportamento por meios coercitivos legais e o controle pela própria comunidade para conservação ambiental. A partir da análise de princípios elencados por Elinor Ostrom é feita a avaliação do desempenho institucional em dois estudos de casos no Parque Estadual da Serra do Mar, nos bairros Cota.
\end{abstract}

Palavras-chave: recursos de acesso comum; Garrett Hardin; Elinor Ostrom; Parque Estadual da Serra do Mar.

Biens publicos y recursos de acceso común: instituciones para la conservación en los bairros Cota en el "Parque Estadual da Serra do Mar de São Paulo"

Este artículo tiene como objetivo abordar la discusión sobre el uso y la conservación de los recursos naturales y de acceso común, los remanentes forestales en las áreas protegidas. El uso y el manejo de dichos recursos son tema de diversas teorías, siendo que en el presente artículo se mencionan los teóricos Garrett Hardin y Elinor Ostrom. En una óptica antagónica, Garrett Hardin aborda la problemática de la colectividad en el uso de los recursos, señalando la necesidad de crear controles externos para evitar la explotación excesiva, mientras que Elinor Ostrom entiende la posibilidad de la autonomía de la comunidad para el uso sostenible. Son contrapuntos entre la inducción al comportamiento mediantes acciones coercitivas legales y el control por parte de la misma comunidad para la conservación ambiental. A partir del análisis de los principios postulados por Elinor Ostrom se hace la evaluación del desempeño institucional en el "Parque Estadual da Serra do Mar", en los "bairros Cota".

Palabras clave: recursos de acceso común; Garrett Hardin; Elinor Ostrom; "Parque Estadual da Serra do Mar".

Artigo recebido em 6 fev. 2012 e aceito em 5 set. 2012.

Rev. Adm. Pública - Rio de Janeiro 46(6):1625-47, nov./dez. 2012 
Public goods and common pool resources: institutions that influence the conservation in "bairros Cota", located in the "Parque Estadual da Serra do Mar de São Paulo"

This article presents an in-depth analysis of use and conservation of natural resources and common pool resources, mainly remaining forest in protected areas. The use and management of common pool resources reflect different analysis, being the basis of this article the debate between Garrett Hardin and Elinor Ostrom. In an antagonist perspective Garret Hardin issues the problems of the collective use of these resources with external regulators to avoid over exploration while Elinor Ostrom observes a greater autonomy of the communities on the sustainable use of these resources. The distinctive views present counterpoints between the inclination of coercive legal means and the own controls of the community. From the principles defined by Elinor Ostrom, this text presents the evaluation of the institutional performance of two cases in "bairros Cota", located in the "Serra do Mar" State Park.

KEY WORDs: common pool resources; Garrett Hardin; Elinor Ostrom; "Serra do Mar" State Park.

\section{Introdução}

Este artigo visa abordar o embate do uso e da conservação dos recursos naturais e de acesso comum, tema que é cada vez mais presente no debate sobre desenvolvimento sustentável.

A instituição de áreas protegidas tem sido um importante mecanismo para conservação da biodiversidade e dos recursos naturais. Desde a criação do primeiro parque, a implantação de áreas protegidas evoluiu e se aprimorou; entretanto, uma questão fundamental permanece: como deve ocorrer, ou não, o convívio entre o homem e os remanescentes florestais nas áreas protegidas.

Os remanescentes florestais possuem uma grande biodiversidade, prestando diversos serviços ambientais como a manutenção do ciclo hídrico, responsável pela qualidade e quantidade de água; a regulação das condições climáticas, tais como temperatura e precipitação; a proteção do solo, associada à fertilidade e ao controle da erosão; a renovação do ciclo de nutrientes, com armazenamento e renovação de carbono, nitrogênio e oxigênio e o sequestro de carbono; a absorção de poluentes; e a fixação fotossintética da energia solar (Benjamin, 2001).

O Parque Estadual da Serra do Mar, criado em 1977, em seus 315 mil hectares, contribui para a conservação de $19 \%$ do total de espécies de vertebrados do Brasil e $46 \%$ da Mata Atlântica. Protege 53\% das espécies de aves, 39\% dos anfíbios, 40\% dos mamíferos e 23\% dos répteis registrados em todo o bioma, conforme consta em seu plano de manejo (São Paulo, 2006). Pesquisas desenvolvidas em áreas do parque demonstram também a influência da cobertura florestal na manutenção da qualidade da água. Em Cubatão, a unidade sofre um ponto de estrangulamento, resultando num pequeno corredor que é responsável pela conexão dos grandes fragmentos do norte e do sul e conservação das águas que abastecem a Baixada Santista. 
No Brasil o tema foi normatizado pelo Sistema Nacional de Unidades de Conservação, que instituiu diferentes categorias de Unidades de Conservação (UCs), algumas permitindo o uso sustentável dos recursos naturais, chamadas de "Uso Sustentável", e outras possuindo um uso mais restrito, de "Proteção Integral".

O uso e a conservação de bens públicos e dos recursos de acesso comum são temas de grandes embates, cabendo destacar entre os ambientalistas e socioambientais, sobre áreas protegidas e comunidades tradicionais residentes, e entre Garrett Hardin e Elinor Ostrom, foco deste artigo, a possibilidade de uma comunidade se organizar para conservar seus recursos naturais.

Garrett Hardin identifica a necessidade de um controle externo, governamental ou de instituições privadas, para evitar a superexploração e degradação dos recursos, pois entende não ser possível sua conservação. Essa visão aproxima-se da abordagem e ideais propostos pelos ambientalistas, propondo a intervenção estatal para proteção e recuperação da biodiversidade.

Elinor Ostrom vê a possibilidade da autonomia da comunidade no uso sustentável desse recurso, entendendo que os indivíduos não são apenas atores racionais e que possuem valores que podem condicionar o uso predatório dos recursos. Os apontamentos feitos nessa corrente são coerentes com os ideais defendidos pelos socioambientalistas.

A partir da aplicação de oitos princípios elencados por Elinor Ostrom em dois estudos de caso nos bairros Cota no Parque Estadual da Serra do Mar (Pesm) é feita a avaliação do desempenho institucional visando verificar regras formais e informais que influenciam no uso dos recursos naturais.

Este artigo está baseado numa análise proposta na dissertação: Governando os comuns ou para os comuns? Gestão de áreas protegidas e os arranjos institucionais da política ambiental no Estado de São Paulo (Sabbagh, 2010).

\section{Bens públicos, recursos naturais e recursos de acesso comum}

Previamente à apresentação dos casos, são expostas as principais definições sobre bens públicos, recursos naturais e recursos de acesso comum, que a legislação brasileira e a microeconomia conceituam.

A Constituição Federal estabelece quais são os bens da União, dos estados federados e dos municípios e o Código Civil conceitua como bens públicos aqueles que pertencem às pessoas jurídicas de direito público, sendo os demais bens particulares. Entre os bens públicos, estão aqueles bens de uso comum do povo, tais como rios, mares, estradas, ruas e praças (Brasil, 1988, 2002).

De acordo com a Política Nacional do Meio Ambiente, a atmosfera, as águas interiores, superficiais e subterrâneas, os estuários, o mar territorial, o solo, o subsolo, os elementos da biosfera, a fauna e a flora são considerados recursos ambientais (Brasil, 1989). 
Para a microeconomia, bens públicos não são aqueles de domínio público e sim aqueles que possuem duas características: não são rivais e nem excludentes, ou seja, o fato de uma pessoa usar determinado bem não reduz a disponibilidade para outros e as pessoas não são impedidas de usar esse bem. E, nessa teoria, recursos comuns são aqueles rivais, mas não excludentes, de modo que as pessoas não são impedidas de usá-los, mas o uso por uma pessoa pode prejudicar a disponibilidade para os demais (Mankiw, 2005).

Deste modo, a maioria dos recursos ambientais pode ser entendida como recursos comuns, pois seu uso pode prejudicar a disponibilidade para os demais, e, apesar das regras, as pessoas não são impedidas de usá-los.

As teorias institucionais também propõem definições sobre bens públicos e recursos de acesso comum. Por instituições, foco de estudo dessa teoria, apreende-se que são mecanismos estabelecidos pelo homem, projetados para alterar a resposta comportamental humana em determinada situação física e social. São regras formais e informais, em uso, que as pessoas reconhecem em dada situação. Regras formais incluem a legislação, as decisões do Executivo e do Judiciário, além de contratos entre particulares (Ostrom, 2005).

Na visão institucionalista, a conceituação de bens públicos e de recursos de acesso comum é abordada de maneira semelhante à microeconomia. Dois atributos são considerados nas análises de bens: a capacidade de exclusão e de subtração. A exclusão é relacionada à dificuldade de restringir os beneficiários da provisão dos bens e a subtração refere-se ao impacto que um indivíduo causa ao subtrair seu uso no total disponível, afetando o consumo de outros (Ostrom, 2005).

Um bem público, nessa teoria, é entendido como um recurso cuja utilização não gera uma subtração perceptível do total e que pode ser usado conjuntamente, sendo difícil a exclusão, pois o uso por uma pessoa não limita o uso por outra. São bens que geram vantagens indivisíveis em benefícios de todos. E, na mesma lógica, os recursos de acesso comum referem-se a recursos naturais ou feitos pelo homem, que podem ser subtraídos e para os quais é difícil excluir um usuário por serem suficientemente grandes, mas sua superexploração afeta sua integridade, dependendo de instituições que possam garantir seu manejo sustentável. Nesse caso, os recursos ambientais como florestas, oceanos, recursos pesqueiros e estratosfera podem ser entendidos como recursos de acesso comum (Ostrom, 2008; Ostrom e Tucker, 2009).

\subsection{Uso dos recursos naturais e dos recursos de acesso comum}

Enquanto as leis visam tratar de dominialidade, as definições da microeconomia e do institucionalismo abordam o viés da disponibilidade e do uso, sendo a problemática de seu esgotamento a origem dos embates. E no estudo sobre o uso de recursos naturais e de acesso comum, dois importantes referenciais teóricos são abordados: Garrett Hardin e Elinor Ostrom.

Garrett Hardin ficou famoso com seu artigo publicado em 1968 com o nome de "The tragedy of the commons" ("A tragédia dos comuns"), na Science. Hardin, por meio de uma metáfora, traz uma experiência hipotética de propriedades com rebanhos e com acesso comum 
aos recursos naturais, abordando a problemática de superexploração e destruição. Esse seria o resultado quando indivíduos exploram recursos de acesso comum, demonstrando a importância da atuação de um membro externo, seja ele o Estado ou a privatização do bem.

Hardin afirma que a degradação dos recursos naturais é inevitável sempre que muitos utilizam o recurso finito, pois indivíduos só visualizam os benefícios próprios e de curto prazo (Ehlers, 2003).

As ideias popularizadas por Hardin tornaram-se explicações amplamente aceitas sobre exploração de recursos manejados de forma comunal, segundo Fenny e colaboradores (2001), tornando-se uma sabedoria convencional nos estudos ambientais. Para Ostrom (2008), "The tragedy of the commons" tornou-se um simbolismo da degradação ambiental, que é esperada quando muitos indivíduos usam recursos escassos.

Em seus livros, Garrett Hardin tem como tema principal o crescimento acelerado da população, atentando que, se não forem impostas restrições, a população mundial não parará de crescer. E no contexto de bens e recursos naturais finitos, o planeta deverá chegar a um colapso.

Hardin (1993) elenca os problemas causados pelo número cada vez maior de habitantes, ironizando, inclusive, se a solução seria mudar para outros planetas. E com a existência de recursos limitados, sua alocação passa a ser um dilema mundial, tornando-se um dos principais problemas dos relacionamentos humanos.

Para o autor, por onde o homem passa, historicamente, verifica-se que ele coloniza, destrói e depois muda para outro lugar. Em seu livro Living within limits, o autor retoma Malthus e suas teorias. Mesmo com os erros verificados em suas discussões, Hardin relembra que as teorias malthusianas sobre o crescimento da população demonstram-se verdadeiras, não necessariamente nos mesmos fatores numéricos, mas a preocupação deve ser real.

$\mathrm{O}$ autor afirma que os aspectos individuais são muitas vezes mais valorizados do que interesses comunitários e que a liberdade dos bens comuns conduz à ruína de todos. Dado que não há saída racional, são necessários mecanismos de controle.

Em seu artigo na Science, Hardin propõe duas saídas: a privatização do bem ou seu controle pelo Estado. Diversos autores reconhecem que Hardin acredita que o controle estatal é a melhor saída, principalmente diante dos recursos naturais limitados. Para o autor, algumas soluções passarão por coerção mútua, determinadas por leis. A democracia, segundo ele, não demanda unanimidade, mas opções aceitas pela maioria. E coerção governamental é requerida para prevenir o intransponível.

Assim, são necessários arranjos sociais, com coerção mútua para acordos da maioria da população afetada, o que não será perfeito, mas preferível. O autor também aborda que os desafios ambientais não serão superados pelas leis tradicionais, sendo necessárias leis legítimas que não sejam apenas aplicadas por burocratas.

Quando o choque de interesses se revelar demasiado violento, convirá que a decisão seja tomada, imposta e sancionada, por respeito pelas maiorias. Mas também não é possível, de acordo com o autor, esperar que o governo seja soberano e arque com todo o trabalho e todas as consequências. 
A temática abordada por Hardin, conforme apontada por Ostrom (2008) e Ost (1997), não é algo novo nas discussões teóricas. O uso dos recursos comuns é abordado, primeiramente, por Aristóteles, quando levanta a questão de que o que é comum ao maior número de indivíduos constitui objeto de menor cuidado, pois o homem tende a negligenciar o que é comum.

Para Ost (1997), o poder público deve intervir, com vista a assegurar uma proteção que a propriedade e o mercado se revelaram incapazes de garantir por si próprios. Segundo o autor, o Estado é intimado a reagir.

Para Fenny e colaboradores (2001), o modelo de Hardin é compreensivo, mas incompleto. Suas conclusões sobre livre acesso e ausência de restrições aos comportamentos individuais negligenciam o papel dos arranjos institucionais que geram a exclusão e a regulação do uso.

De acordo com McKean e Ostrom (2001), "The tragedy of the commons" aponta para os prejuízos de um regime de livre acesso, onde há ausência de direitos de propriedade ou de regimes de manejo, e a superexploração é algo esperado. Isso é diferente de os recursos serem manejados por uma comunidade. O regime comum oferece um caminho para a manutenção da exploração limitada de um sistema de recursos ameaçado ou vulnerável, associado a monitoramento e coação.

Nesse sentido de estudar a problemática dos bens comuns, a abordagem de Elinor Ostrom, cientista política ganhadora do Prêmio Nobel em 2009, concentra-se na solução coletiva dos usos dos recursos de acesso comum, principalmente nas teorias institucionalistas.

As teorias institucionalistas questionam os pilares do pensamento neoclássico, em especial a crença no mercado, conforme explicado por Ehlers (2003). Para os institucionalistas, a falha está em tratar os indivíduos como seres independentes e somente racionais.

Os institucionalistas entendem que o ser humano nem sempre maximiza as riquezas, de modo que as escolhas podem ser determinadas por valores, crenças, reações altruístas ou imposição de autorrestrições, que podem balizar a decisão humana (Ehlers, 2003).

$\mathrm{Na}$ vertente específica da escolha pública do institucionalismo, defendida por Elinor Ostrom, os teóricos buscam entender como são as escolhas individuais entre as opções existentes. Entende-se que os agentes definem suas próprias restrições, sejam físicas, naturais, tecnológicas, legais ou de contexto. Consideram, ainda, que o Estado deve assegurar os direitos, particularmente os de propriedade. Segundo Ehlers, a intervenção estatal deve ser mínima e a autonomia também é entendida como um aspecto importante para a escolha pública.

Buscando entender as escolhas individuais entre as regras existentes, os teóricos da vertente institucionalista defendem que as comunidades podem ser capazes de governar e manejar seus recursos de acesso comum, com decisões que vão além das racionais.

Para compreender este processo, Ostrom sugere uma análise institucional para verificar quais regras formais e informais influenciam uma comunidade ao uso sustentável dos recursos de acesso comum, considerando que a coerção, repressão e controle centralizado do Estado não são as únicas soluções para esse dilema. Ostrom não ignora os valores dados pelos indivíduos na obtenção de benefícios de curto prazo e em sua atuação oportunista, entretanto, 
entende que a privatização e o Estado são incapazes de reduzir o problema do oportunismo (Ehlers, 2003).

O desafio de Ostrom é tentar entender por que é possível que algumas comunidades se organizem para governar e manejar os bens de acesso comum e outras não. A autora elenca alguns fatores que influenciam na capacidade de manejo sustentável de recursos pelas comunidades: existência de normas, formais e informais, monitoramento e sanção, benefícios e custos bem definidos. Isso requer uma sistemática de acesso e difusão de informações e sentimento de confiança e de comunidade. Trata-se de um comprometimento da comunidade em organizar-se para obter benefícios de longo prazo.

A autora entende que não é necessária uma intervenção externa, como do Estado ou de instituições privadas. Os indivíduos são capazes de se organizar e autogovernar de modo que as decisões sejam coletivas e haja uma efetiva conservação dos recursos de acesso comum.

Ostrom (2008), abordando a temática da tomada de decisão de atores individuais para o interesse coletivo, entende que se trata de princípios, que muitas vezes estão implícitos nas instituições daquelas comunidades onde o recurso é bem manejado. São as regras de uso das comunidades, pelo direito ou crença, bem como o valor dado a determinado bem, que vai além do racional.

Segundo Moran (2009), diversas podem ser as variáveis contextuais para a tomada de decisão dos indivíduos: pobreza, riqueza, tamanho da população, características geográficas, topográficas, biológicas e de solo da região, preços agrícolas, uso da terra, valor da terra, informações disponíveis, normas legais e regras formais e informais, cultura, característica dos atores, infraestrutura e incentivos do mercado.

Para Ostrom (2005), são oito os princípios que favorecem uma ação coletiva para a utilização de recursos de acesso comum:

1. Fronteira da comunidade para o uso desses recursos deve ser clara, com limites bem definidos e com critérios para o ingresso a grupos de usuários;

2. Regras de uso desses recursos devem ser claras e bem definidas;

3. Usuários devem ter o direito de modificar suas regras de uso desses recursos ao longo do tempo;

4. Infrações às regras estabelecidas para o uso desses recursos devem ser monitoradas;

5. Existência de um sistema de sanções graduais, de acordo com o tipo de infração;

6. Existência de mecanismos para a solução de conflitos no uso desses recursos;

7. Reconhecimento mínimo de direitos para organização e estabelecimento de regras próprias no uso de acesso comum;

8. Existência de empreendimentos inter-relacionados, quando se tratar de um grande sistema.

Mesmo com o equilíbrio no uso dos recursos de acesso comum, existem os chamados free riders, que, apesar das normas existentes, do monitoramento e das sanções, irão desres- 
peitar as regras. São oportunistas que não participam dos esforços coletivos, mas se aproveitam dos bens gerados (Ostrom, 2008).

Considerando que as decisões individuais podem ser determinadas também por valores e crenças, que vão além da maximização das riquezas, não há uma aceitação e adaptação perfeita de todos os membros da comunidade. A natureza da organização e das relações, o equilíbrio organizacional e os mecanismos de busca pela satisfação podem direcionar atitudes das pessoas da comunidade, minimizando o oportunismo e os free riders (Simon, 1978).

Para a autora, o importante é construir e manter instituições eficientes diante de interesses e agentes diversos e frequentemente conflituosos. A análise dos oito princípios permite verificar o desempenho institucional, avaliando a capacidade de determinadas comunidades em se organizarem para o uso sustentável dos recursos de acesso comum. Esse é o foco de análise proposto neste artigo para os casos estudados.

\section{Apresentação dos casos}

Neste artigo é apresentada a aplicação dos oito princípios que favorecem uma ação coletiva para a utilização de recursos de acesso comum, propostos por Elinor Ostrom, com base em dois casos.

Os casos foram escolhidos em função de ser uma ocupação de residentes que envolve o uso de recursos naturais no interior de uma unidade de conservação de proteção integral, que possui usos restritivos. A existência de informações, dados populacionais e imagens de satélites também foram critérios para a seleção dos casos.

Para a análise dos casos foram feitas pesquisas em referenciais bibliográficos, entrevistas com atores sociais e dados quantitativos de levantamentos realizados pela companhia habitacional e da polícia militar ambiental. Como escolha do objeto de estudo foi selecionado o Parque Estadual da Serra do Mar no estado de São Paulo, por sua importância social, econômica e ambiental. Trata-se de uma unidade de conservação em cuja categoria não é permitido o uso dos recursos naturais, com exceção para finalidades de pesquisa e educação ambiental, e não pode haver moradia.

As duas comunidades escolhidas residem em áreas não permitidas, a Cota 400 e a Água Fria, ambas localizadas no município de Cubatão.

Um dos casos envolve uma ocupação que teve pequenos decréscimos de vegetação nativa com as ocupações existentes, e outro onde houve uma maior degradação ambiental, sendo ambos verificados nos anos de 2000 e 2007, a partir de imagens de satélite comparativas para examinar a situação da cobertura florestal local.

Foram realizadas entrevistas, complementando a análise das imagens de satélites, listadas a seguir:

I. Líder da Água Fria

II. Líder da Cota 400 
O roteiro elaborado visou obter informações das lideranças sobre o valor dado aos recursos naturais de acesso comum nos núcleos, quais as informações disponíveis, qual o valor dado às regras e às penalidades, benefícios esperados de morar na região e possibilidade de ação conjunta da comunidade (Sabbagh, 2010). As entrevistas ocorreram previamente ao início do programa estadual de realocação das famílias destas áreas e ao trabalho social realizado pelo órgão habitacional de sensibilização das famílias, com objetivo de entender a percepção dessas lideranças sobre o papel do Parque Estadual da Serra do Mar e a organização da comunidade para conservação dos recursos naturais.

Foram também realizadas entrevistas com outros atores envolvidos no processo:

III. Capitão da Polícia Militar Ambiental da área, que acompanhou o desenvolvimento do papel dos soldados na região, apontando a necessária mudança da atuação, de só fiscalização, para um desempenho integrado de prevenção e punição;

IV. Antiga gestora do Parque na região de Cubatão - Núcleo Itutinga Pilões, que atuou de forma mais participativa na gestão da unidade, abordando a importância de envolver as comunidades na proteção dos recursos naturais;

V. Jornalista de A Tribuna da Sucursal de Cubatão, que desde a década de 1970 acompanha os programas, tanto do estado, como do município, de conservação da serra do Mar e de atuação em face dos desastres ocorridos na região, torcendo para que o programa de realocação das famílias destes bairros fosse bem-sucedido, dado que os demais não haviam sido concretizados;

VI. Gestora da Companhia de Desenvolvimento Habitacional e Urbano do Estado de São Paulo (CDHU) responsável pelo trabalho social e de realocação, com sede em Cubatão, que liderou o processo de envolvimento da comunidade e da implementação do programa, num esforço contínuo de convencimento da população, num contexto de inseguranças.

A metodologia elaborada por Elinor Ostrom teve o papel de balizar a realização das visitas de campo e colaborar na identificação das variáveis e princípios que favorecem uma ação coletiva para a utilização de recursos de acesso comum, para aplicação do modelo para a avaliação do desempenho institucional dos dois casos.

\subsection{Programa Serra do Mar}

Lançado no início de 2007, o Programa de Recuperação Socioambiental da Serra do Mar, do Governo do Estado de São Paulo, numa parceria das Secretarias de Habitação e do Meio Ambiente, com financiamento do Banco Interamericano de Desenvolvimento (BID), prevê o atendimento de 7.760 famílias moradoras de áreas irregulares do parque, em Cubatão. Ao todo, 5.350 famílias deverão deixar áreas de risco ou de preservação ambiental da serra do Mar. Para realocar essas pessoas, além da oferta de moradias em outros municípios da Baixada 
Santista, a CDHU, ligada à Secretaria de Habitação, está construindo três bairros em Cubatão: o residencial Rubens Lara, no Jardim Casqueiro, e os residenciais Vila Harmonia e Parque dos Sonhos, que somam 3.594 moradias (São Paulo, 2012).

Desde o início do programa até o início de 2012, 2.093 famílias já deixaram as áreas de risco da serra do Mar. Dessas, 1.549 foram para novas moradias da CDHU, sendo 1.077 em Cubatão e 472 em outros municípios da Baixada Santista. Outras 544 receberão auxílio moradia até que seja viabilizada uma moradia definitiva.

Além de novas moradias, a CDHU irá urbanizar os bairros Cota 95/100, Cota 200 e Pinhal do Miranda. As 2.410 famílias que ficarão em áreas já consolidadas da serra do Mar serão atendidas com serviços básicos e terão a escritura definitiva do imóvel.

Neste Programa, a Secretaria do Meio Ambiente responsabilizou-se pela recuperação florestal das áreas desocupadas e a implantação de equipamentos de uso público e de educação ambiental.

\subsection{Cota 400 e Água Fria}

A seguir são apresentadas as observações feitas em campo e as principais informações obtidas nas entrevistas. Atualmente, a Cota 400 e a Água Fria, por estarem dentro do Parque Estadual da Serra do Mar, devem ser desocupadas, com a adequada realocação das famílias que atualmente habitam esses núcleos habitacionais. Reforçando a necessidade de desocupação, um mandato judicial do Ministério Público, no qual o Governo do Estado é réu, determina a realocação destas famílias nas áreas do Parque em Cubatão. O agravante do núcleo da Água Fria é que, pelo Código Florestal, trata-se de uma Área de Preservação Permanente, sendo sua ocupação também um crime ambiental. Pelo Programa de Recuperação Socioambiental da Serra do Mar, está prevista a remoção integral da população destes dois núcleos.

Com a existência desse Programa, alguns órgãos governamentais passaram a ficar mais presentes nestas áreas de Cubatão. A Polícia Militar Ambiental tem seu contingente reforçado, com acompanhamento mais frequente do gestor do Núcleo Itutinga Pilões pela Fundação Florestal; a Secretaria do Meio Ambiente desenvolve novos projetos de educação ambiental; o Instituto Florestal elabora projetos de recuperação florestal; a CDHU inicia seu trabalho de construção de unidades habitacionais para realocação das famílias e faz o atendimento social da população.

Para a consecução deste Programa, no período de abril a junho de 2007, a Secretaria de Habitação/CDHU realizou um arrolamento domiciliar e a caracterização socioeconômica de cada núcleo habitacional em Cubatão (CDHU, 2007). Esses dados serão explicitados a seguir.

O núcleo Cota 400 tem origem em um alojamento da rodovia Anchieta, em 1939, e transforma-se numa área residencial com permanência das famílias após o término das obras. Essa área, que incorpora a Cota 500, está localizada no $\mathrm{km} 48$ da pista descendente da via Anchieta e é atravessada por essa via em dois pontos, dividindo-a em três setores: norte, entre pistas e barra funda (CDHU, 2007). 
As ruas principais são afastadas, mas vielas e becos são de difícil acesso. A energia elétrica não abrange todas as moradias, sendo parte delas irregular. O sistema de abastecimento de água e de coleta de esgoto é precário. O lixo é depositado em caçambas e posteriormente retirado. Não há posto de saúde nem escolas. Quando as pistas da Anchieta são interditadas e fechadas para manutenção, não há meios de saída do núcleo, a não ser a pé.

O núcleo Cota 400/500 apresentava, em 2007, 217 domicílios com 637 habitantes. Em média, são 3,5 pessoas por domicílio. Do total, 42,3\% dos domicílios contavam com $2 / 3$ pessoas; e aquelas com mais de 60 anos representando 6,6\%. São do sexo feminino 48,2\% dos indivíduos (CDHU, 2007).

A caracterização das edificações realizada pela CDHU em 2007 apontou que 89,4\% das edificações estavam ocupadas, sendo $2 \%$ pontos comerciais. Dos domicílios, $65,9 \%$ eram de alvenaria, $17,5 \%$ são do tipo misto e $11,5 \%$ de madeira aproveitada.

A caracterização da CDHU dos responsáveis pelos domicílios revelou que 20,4\% moravam na área entre seis e 10 anos; 26,02\% entre 11 e 20 anos; 13,8\% entre 21 e 30 anos e apenas $7,1 \%$ há mais de 30 anos.

De maneira geral, segundo a líder entrevistada, as pessoas trabalham nas empreiteiras, muitas vezes com serviços temporários, e nas indústrias em Cubatão. As famílias não desenvolvem plantios para a subsistência. No máximo possuem alguns galos e galinhas.

Iniciado como um acampamento do DER, o núcleo foi se consolidando com a construção de novas casas, principalmente para filhos, netos e parentes próximos. Por exemplo, em uma das casas visitadas foi verificado esse tipo de expansão: um residente se instalou logo após a instituição do Pesm sem saber que não podia morar lá. Ele diz ter sido incentivado pela prefeitura e começou alugando uma casa de madeira do DER e, após anos de moradia, conseguiu comprar o imóvel. Ao longo dos quase 25 anos que esteve nessa área construiu outras quatro casas de cimento e tijolo para seus filhos e netos, mas sua casa permaneceu no mesmo estado precário em função do tempo, umidade e cupim. A manutenção dessa precariedade funciona como um atestado do tipo de ocupação originária dos acampamentos do DER.

Já o núcleo Água Fria tem origem com sítios de cultivadores de banana. Em 1910 serviu como base da construção da Companhia Santista de Papel, onde foram alojados alguns sítios com cultivo de eucalipto, atraindo residentes para trabalharem na companhia. É uma área tombada pela Resolução Condephaat no 40/85, e, de acordo com o Código Florestal, está numa Área de Preservação Permanente (APP). Essa ocupação está próxima ao ponto de captação de água da Sabesp, que abastece a Baixada Santista, com população estimada de 1,6 milhão de habitantes.

Apresenta aproximadamente dois quilômetros de extensão, margeando o rio Cubatão. A rua principal é de terra batida e as vielas e becos não têm pavimentação. A energia elétrica existente não abrange todas as moradias, sendo parte delas irregular. E o sistema de abastecimento de água e esgoto é precário. Por indicação de uma das gestoras do parque, as casas na Água Fria, em sua maioria, possuem fossas sépticas, visando uma melhor destinação dos dejetos, em função da ausência de sistema de saneamento. O lixo é depositado em caçambas e posteriormente retirado. 
O núcleo Água Fria apresentava, no momento do diagnóstico, 1.352 domicílios com 3.980 habitantes. Do total, 43,1\% dos domicílios contavam com 2/3 pessoas, sendo aqueles com mais de 60 anos equivalente a 5,5\%. Eram do sexo feminino 50,7\% dos indivíduos (CDHU, 2007).

A caracterização das edificações realizada pela CDHU apontou que $88,7 \%$ das edificações estavam ocupadas e 5\% eram ponto comercial. Dos domicílios, $12,6 \%$ era de material improvisado e 15,3\% de madeira aproveitada, sendo grande parte de alvenaria.

A caracterização da CDHU dos responsáveis pelos domicílios revelou que 14\% moravam na área entre 6 e 10 anos; 23,2\% entre 11 e 20 anos; 14\% entre 21 e 30 anos e apenas 6\% há mais de 30 anos.

Segundo o líder comunitário, as pessoas trabalham principalmente nas empreiteiras, em Cubatão. Em suas residências não desenvolvem plantios para a subsistência. Apenas alguns moradores mais antigos mantiveram a cultura de chácaras com pequenas hortas. São, em sua maioria, residentes. Há também pequenos centros comerciais e igrejas.

Entre os moradores, alguns mais antigos chegaram antes da instituição do Pesm. Até a década de 1980, pouco mais de 50 famílias habitavam a região. O núcleo foi adensado em consequência da atração cada vez maior de mão de obra para Cubatão, com famílias que não tinham onde morar. A Água Fria demonstra ser um bairro de fácil acesso, plano e mais próximo das indústrias. O núcleo cresceu também para acomodar a chegada de parentes, com a construção de casas para filhos, netos e irmãos.

Tanto na Cota 400 como na Água Fria verifica-se que não há controle sobre o aumento populacional do núcleo e, por muitos anos, as invasões foram estimuladas por troca de votos em períodos eleitorais. Novos parentes dos residentes chegam e ninguém é avisado. Segundo a líder da Cota 400, em 2000 foram contadas 182 casas em seu núcleo e em 2007, 202.

De acordo com o líder da Água Fria há alguns anos, por iniciativa do gestor do Parque da Serra do Mar, pelo órgão ambiental, tentou-se fazer um congelamento das ocupações, controlado pela própria população. Essa iniciativa não obteve sucesso em sua continuidade, mas a adesão da população residente foi grande. Outra proposta de alguns membros da Água Fria, estimulados pelo gestor, foi a implantação de uma cerca, principalmente próxima ao rio Cubatão, para conter o aumento populacional, permitindo a continuidade daqueles que ocupam esta área.

Quando questionados, os líderes da Cota 400 e da Água Fria abordaram a importância do Pesm na região, associado, principalmente, ao clima ameno e à vegetação conservada.

Em função da proximidade do Núcleo Itutinga Pilões e dos gestores, inclusive com sinalizações e portais, verifica-se uma maior adesão da Água Fria ao parque. Entretanto, em ambos os casos, os líderes disseram não concordar com os motivos pelos quais estão sendo retirados desses núcleos. Acham que deveriam continuar na área e participar mais do processo de decisão.

Verifica-se também que os principais desmatamentos realizados nesses núcleos são para a construção de novas casas. Segundo informações da polícia ambiental, são poucas as infrações ambientais de caça e pesca na região, ou mesmo para realização de plantios. 
Entre 2002 e 2009, na totalidade dos bairros Cota, foram lavrados 26 autos de infração, sendo três relativos à caça e os demais a desmatamento da flora. Na Água Fria, entre 2002 e 2009, foram lavrados 107 autos de infração, sendo apenas dois relativos à caça, um à mineração e o restante referente ao desmatamento da flora (Polícia Militar Ambiental, 2010).

Verifica-se que na Água Fria há um aumento considerável em 2007 dos autos de infração, relativo a mais de 78\% do total entre 2002 e 2009, ano em que foi reforçada a fiscalização com a ampliação do contingente para 100 policiais. Nos anos posteriores, mesmo com a manutenção do nível da fiscalização, houve uma queda nas infrações, pois as principais irregularidades foram observadas no primeiro ano. No que diz respeito à Cota 400, com uma densidade populacional pequena quando comparada aos demais núcleos, teve o menor número de irregularidades.

Desde 2007 reformas e ampliações passaram a ser controladas pela Polícia Militar. A partir da análise de novos telhados, por sobrevoos realizados pelos policiais, verifica-se um congelamento desses núcleos habitacionais.

No começo a atuação da Polícia Militar Ambiental não era bem-vista pelos residentes, de acordo com os policiais, mas com o tempo foram ganhando a confiança de muitos moradores e hoje é um dos principais canais de comunicação com o governo. Entretanto, segundo a coordenadora social da companhia habitacional, ainda há reclamações a respeito da presença constante dessa fiscalização.

Com as operações militares, a partir da verificação de desmatamentos irregulares, principalmente para a construção de novas casas ou para ampliação das existentes, diversas advertências e multas foram aplicadas.

Algumas multas chegaram ao valor de $\mathrm{R} \$ 10$ mil, o que passou a ser inviável para alguns moradores, em função de sua baixa renda. Como recurso, alguns residentes apresentaram Atestado de Pobreza para demonstrar a inviabilidade do pagamento. Foi o custo da ilegalidade, do desmatamento.

Segundo a líder da Cota 400, as pessoas da comunidade tinham conhecimento de que estavam no Pesm, mas por muitos anos não souberam que não poderiam ocupar aquelas áreas por ser parque e que eram incentivadas a morar na região.

Um dos gestores do parque, que fez uma gestão mais próxima às comunidades, promoveu palestras informativas e fez projetos conjuntos. Em alguns casos a confiança foi tal que os moradores denunciavam novas invasões.

Até então, o custo de invadir e construir era baixo, ou quase nulo, mas com o aumento da fiscalização, o custo das multas passou a ser alto, inibindo o exercício de algumas ações irregulares.

Morando em habitações da CDHU novos custos passarão a fazer parte da vida destas famílias, como mensalidade da aquisição do imóvel e pagamento pelo fornecimento de água e energia. Mas, de acordo com a coordenadora social, as famílias querem ficar na legalidade e, de maneira geral, não se importam de pagar suas contas, se isso significar que serão reconhecidos como cidadãos. 
Pelo pouco uso de recursos de acesso comum e o uso da terra para exercício de suas atividades, as regras vigentes da comunidade são principalmente para a obtenção de energia e abastecimento de água. A divisão dos terrenos, muitas vezes, foi condicionada por influência dos políticos em época de eleição, conforme abordado pelo jornalista.

Tanto na Cota 400 como na Água Fria, o sistema de fornecimento de energia elétrica presente é da empresa Bandeirante Energia S/A, entretanto predomina o sistema irregular.

$\mathrm{O}$ abastecimento de água ocorre por canos ligados diretamente em nascentes na serra do Mar. Esta solução local de fornecimento de água para a população dos bairros localizados na serra do Mar é chamada de "Projeto Água Limpa", instalado em 1973 por particulares e administrado pela mesma família até o presente momento (Projeto Água Limpa, 2010).

Pelo fato de a Sabesp não poder atender a esses núcleos por serem ocupações irregulares no interior do Pesm, o "Projeto Água Limpa" foi expandido para atender à maioria das casas nos bairros Cota e Água Fria. Há um processo do Ministério Público sobre a captação irregular, mas a suspensão desse sistema implicaria o fim do abastecimento de água às residências que não possuem alternativa.

Apesar das ações já em execução do Governo do Estado de São Paulo para a construção de novas casas em 2007, as famílias não acreditavam que deixariam o local. Desde 1975, diversos órgãos, municipais e estaduais, abordam a realocação das famílias nos Bairros Cota.

Apenas aquelas que vivem em péssimas condições e em áreas de risco querem sair para uma habitação oferecida pela CDHU, os demais não querem, segundo os líderes. Entretanto, de acordo com a coordenadora social, as famílias estão deixando de questionar sua saída e procurando a melhor habitação possível para sua realocação, o que é verificado com a adesão cada vez maior ao programa. De certa forma, alguns não querem sair por falta de informações e por insegurança sobre o destino e quais benefícios obterão.

Famílias da Cota 400 constantemente se organizam para impedir sua retirada, ou no caso de sua saída, requisitar indenizações por serem das famílias dos operários da construção da via Anchieta e que chegaram anteriormente ao Pesm. Muitos vão ao DER requisitar um atestado de que um membro da família participou da construção da estrada. Inclusive, a manutenção das casas antigas, mesmo que em situação de precariedade, visa atestar isso.

Na Água Fria os moradores verificaram a possibilidade de contratação conjunta de um advogado para defender suas necessidades diante das propostas do Governo do Estado, reunindo-se constantemente para se atualizarem e verificarem os próximos passos. Houve também apoio da Prefeitura Municipal a esse movimento.

Para atender ao mercado existente nessa área, o governo, por meio da Secretaria de Emprego e Relações do Trabalho, tem incentivado a realização de cursos de capacitação para os moradores desses núcleos. Entretanto, as pessoas não atendem necessariamente às qualificações exigidas nas indústrias.

Para a coordenadora social, a adesão das famílias ao Programa da Serra do Mar é cada vez maior, com participação ativa nas reuniões, com exceção de alguns comerciantes que perderão receita com as mudanças e famílias com casas de grande porte. Uma dessas famílias, por exemplo, possui uma casa de três andares e piscina. Ou mesmo a liderança do "Projeto Água Limpa", que perderá sua renda. 
A CDHU está propondo um novo padrão de construção de habitações, com um projeto inovador de bairros com casas e sobrados que visam atender à demanda desta população com características que não são rurais, mas que também não são urbanas. As unidades contam com medidores individuais de água e gás e aquecimento solar. Além disto, são cercadas de serviços básicos, como centros educacionais, quadras poliesportivas.

O trabalho desenvolvido por Lucy Marion Machado (1996) sobre percepção ambiental em Cubatão apresenta resultados importantes de pesquisas realizadas com moradores nos bairros Cota, abordados nesta análise.

Os moradores entendem que a serra do Mar significa água, altitude, ar, relevo e, principalmente, vegetação. Trata-se do melhor canto da cidade para morar. De acordo com a autora, alguns reforçam: "serve só para morar" (Machado, 1996:110). Não é entendido como um lugar de onde se tira o sustento ou se exerce atividades para sobrevivência, como a realização de plantios.

Quando a população foi questionada sobre quem deve cuidar da serra do Mar, a maioria atribuiu a tarefa às autoridades, sendo a maior parcela para os governos federal e estadual. Pouco se falou da prefeitura.

Numa visão de futuro, os moradores esperam que seus filhos e netos conheçam a serra do Mar como ela é hoje e que estejam próximos dela.

\subsection{Análise dos casos}

Desde os primeiros acidentes e deslizamentos ocorridos em algumas favelas na década de 1980 em Cubatão, as famílias passaram a ser mais questionadas sobre sua ocupação irregular e envolvidas em planos e programas de realocação. Verifica-se que muitas das famílias ficam constrangidas ao falar para representantes do governo que moram na serra do Mar.

De 1977 a 2006 a gestão do Parque Estadual da Serra do Mar foi de responsabilidade do Instituto Florestal. Num modelo de gestão menos participativo, culminou em alguns momentos em que a fiscalização foi extremamente dura e penosa. E mesmo que não seja permitida a existência de populações no interior do Pesm, por ser unidade de conservação da categoria de proteção integral, o crescimento dos núcleos habitacionais e seu adensamento foram observados ano a ano.

Entre 2006 e 2007 há uma mudança no modelo de gestão das unidades de conservação no estado de São Paulo, tendo a Fundação Florestal como órgão responsável pela administração de parques. Apesar das normas sobre parques permanecerem as mesmas, altera-se a percepção do papel das unidades de conservação e necessidade de uma atuação mais participativa nos casos em que envolvem moradias, associada ao fomento ao ecoturismo e ao uso público, com novas bases de vigilância e de visitantes, instalação de portais para o aprimoramento da infraestrutura.

O embate entre ambientalistas e socioambientalistas sobre o papel das áreas protegidas tem contribuído para o aprimoramento da gestão das unidades de conservação, reconhecendo, de um lado, a importância de áreas conservadas, sem interferências, para proteção dos recursos naturais, e, de outro, a atuação de determinadas comunidades tradicionais, que já 
estavam instaladas previamente à criação de áreas protegidas, sobrevivendo e conservando os recursos de acesso comum.

Os ambientalistas defendem que o objetivo principal das unidades de conservação deve ser a preservação dos ecossistemas e de sua biodiversidade, e seus benefícios sociais e econômicos são para a humanidade, em função dos serviços ambientais prestados. E os socioambientalistas sustentam que o objetivo principal das unidades de conservação deve ser a promoção do desenvolvimento sustentável, por meio do aproveitamento racional de seus recursos naturais, em benefício das populações locais.

Além da mudança institucional, em 2007 é instituído o programa para a recuperação da serra do Mar e a fiscalização é reforçada com um contingente de 100 policiais, além de novos vigilantes e um novo gestor do Núcleo Itutinga Pilões. Complementarmente, o Conselho Consultivo é instituído formalmente.

O Conselho Consultivo passa a ser uma instância de disseminação de informações, como um canal para que a população e a sociedade civil da região possam obter informações sobre o Programa e as ações pretendidas pelo Governo do Estado. Entretanto, trata-se de uma instância consultiva e não deliberativa. Novas demandas levantadas pelos conselheiros são levadas aos diretores da Fundação Florestal e aos dirigentes da Secretaria do Meio Ambiente.

Contudo, a existência de canais de comunicação não significa que eles cumpram o papel esperado pelas comunidades, que procuram participar no processo decisório. Faltam mecanismos de empowerment - empoderamento - da população local. Consequentemente, reclamações constantes sobre falta de informação dos líderes da Cota 400 e Água Fria são verificadas e visam demonstrar a insatisfação dessas comunidades que gostariam de participar do processo decisório.

A presença dos policiais militares ambientais demonstrou ser um dos mecanismos garantidores do cumprimento de regras formais, contribuindo para a proteção aos recursos de acesso comum, influenciando a tomada de decisão dos residentes. Um mecanismo que inicialmente foi ostensivo e atualmente busca ser preventivo também.

Na prática, verifica-se que os policiais militares ambientais e os gestores dos parques são aqueles que fazem com que as leis sejam cumpridas e que estão em contato direto com esta população. São aqueles que implementam as políticas instituídas nos níveis hierárquicos superiores, os street level bureaucracy.

Diferentemente de outras ocupações no Parque Estadual da Serra do Mar, observa-se que na Água Fria e na Cota 400 há pouco envolvimento com os recursos naturais. Pelo tipo de atividade que exercem, possuem uma conexão maior com os recursos de acesso comum pela localização de suas moradias. De maneira geral, não são desenvolvidas atividades de subsistência. Na Água Fria poucas famílias mantêm algumas hortas e chácaras, pois a renda é obtida com os trabalhos realizados nas empresas de Cubatão.

Nota-se um perfil de vida associada à proximidade com os recursos de acesso comum, mas não a ponto de uma relação de admiração ou respeito. É um estilo de vida diferente do urbano, que não se adapta a nenhuma situação.

Verifica-se que a falta de relação com os recursos de acesso comum dos núcleos de Cubatão está relacionada, principalmente, com as condições que levaram aquelas pessoas a ocupa- 
rem essas áreas. São famílias, em sua maioria, que pela falta de recursos financeiros não tiveram condições de pagar por moradias melhores em outros lugares e optaram por ocupar essas áreas irregulares. E com os anos foram melhorando suas instalações, mas ainda à custa de serviços públicos inexistentes, com práticas irregulares. Ao longo da história de consolidação desses núcleos habitacionais, houve incentivo à ocupação, em troca de voto e apoio político.

De maneira geral, observa-se que diversos fatores geográficos também condicionaram que a ocupação fosse maior em determinado bairro e menor em outros. Com topografia acentuada, pouco adensamento populacional, difícil acesso e um isolamento quase natural, a Cota 400 diferencia-se da Água Fria, área plana, próxima às indústrias, com fácil acesso e adensada.

Analisando as informações obtidas nas entrevistas e nas observações de campo, são identificados os principais aspectos que atendem aos critérios propostos na teoria de Elinor Ostrom, que visa avaliar a existência de instituições formais e informais que possam impactar ou não o uso dos recursos naturais, alterando ou condicionando o comportamento, a partir dos oito princípios que favorecem uma ação coletiva para a utilização de recursos de acesso comum.

O quadro 1 apresenta o resultado da aplicação do modelo proposto por Elinor Ostrom, com as comparações entre os dois casos, fazendo uma separação entre as regras formais e as informais, considerando o que é estabelecido pelas leis ambientais e o que é praticado pela comunidade, o que necessariamente não significa desrespeito às leis, mas são as regras praticadas.

$$
\text { Quadro } 1
$$

\section{Princípios que favorecem a ação coletiva aplicados a Água Fria e Cota 400}

\begin{tabular}{|c|c|c|c|c|}
\hline Princípios & $\begin{array}{c}\text { Cota } 400 \text { - Regras } \\
\text { Formais }\end{array}$ & $\begin{array}{c}\text { Cota } 400 \text { - Regras } \\
\text { Informais }\end{array}$ & $\begin{array}{c}\text { Água Fria - Regras } \\
\text { Formais }\end{array}$ & $\begin{array}{c}\text { Água Fria - Regras } \\
\text { Informais }\end{array}$ \\
\hline $\begin{array}{c}\text { Fronteira da } \\
\text { comunidade para o } \\
\text { uso dos recursos de } \\
\text { acesso comum deve } \\
\text { ser clara, com limites } \\
\text { bem definidos e } \\
\text { com critérios para o } \\
\text { ingresso de grupos } \\
\text { de usuários. }\end{array}$ & $\begin{array}{c}\text { Fronteira é bem } \\
\text { definida sobre o uso } \\
\text { dos recursos e de } \\
\text { ingressos de grupos. } \\
\text { Por ser um parque, } \\
\text { não pode haver uso e } \\
\text { nem moradia no seu } \\
\text { interior. }\end{array}$ & $\begin{array}{l}\text { Sem definição de } \\
\text { regras no ingresso } \\
\text { de novos residentes. } \\
\text { Famílias recebem } \\
\text { novos parentes sem } \\
\text { avisar ninguém. }\end{array}$ & $\begin{array}{c}\text { Fronteira é bem } \\
\text { definida sobre o uso } \\
\text { dos recursos e de } \\
\text { ingressos de grupos. } \\
\text { Por ser um parque, } \\
\text { não pode haver uso e } \\
\text { nem moradia no seu } \\
\text { interior. }\end{array}$ & $\begin{array}{c}\text { Sem definição de } \\
\text { regras no ingresso } \\
\text { de novos residentes. } \\
\text { Entretanto já } \\
\text { demonstraram } \\
\text { interesse em cercar } \\
\text { o núcleo para evitar } \\
\text { novas ocupações. }\end{array}$ \\
\hline $\begin{array}{l}\text { Regras de uso } \\
\text { dos recursos de } \\
\text { acesso comum } \\
\text { devem ser claras } \\
\text { e bem definidas, } \\
\text { condicionadas à } \\
\text { realidade local. }\end{array}$ & $\begin{array}{l}\text { As regras para uso não } \\
\text { são bem definidas. De } \\
\text { acordo com a norma } \\
\text { legal, num parque não } \\
\text { pode ser feito o uso } \\
\text { dos recursos. }\end{array}$ & $\begin{array}{c}\text { Possuem regras para } \\
\text { o uso de água pelo } \\
\text { Projeto Água Limpa. } \\
\text { Não fazem grandes } \\
\text { desmatamentos, a não } \\
\text { ser para a construção } \\
\text { de novas moradias. } \\
\text { Outra questão é a } \\
\text { manutenção das casas } \\
\text { do DER, mesmo em } \\
\text { condições precárias, } \\
\text { para atestar o tipo } \\
\text { de ocupação, casas } \\
\text { "testemunhos". }\end{array}$ & $\begin{array}{l}\text { As regras para uso não } \\
\text { são bem definidas. De } \\
\text { acordo com a norma } \\
\text { legal, num parque não } \\
\text { pode ser feito o uso } \\
\text { dos recursos. }\end{array}$ & $\begin{array}{l}\text { Possuem regras para } \\
\text { o uso de água pelo } \\
\text { Projeto Água Limpa. } \\
\text { Não fazem grandes } \\
\text { desmatamentos, a não } \\
\text { ser para a construção } \\
\text { de novas moradias. }\end{array}$ \\
\hline
\end{tabular}




\begin{tabular}{|c|c|c|c|c|}
\hline Princípios & $\begin{array}{c}\text { Cota } 400 \text { - Regras } \\
\text { Formais }\end{array}$ & $\begin{array}{c}\text { Cota } 400 \text { - Regras } \\
\text { Informais }\end{array}$ & $\begin{array}{c}\text { Água Fria - Regras } \\
\text { Formais }\end{array}$ & $\begin{array}{c}\text { Água Fria - Regras } \\
\text { Informais }\end{array}$ \\
\hline $\begin{array}{l}\text { Usuários devem ter o } \\
\text { direito de modificar } \\
\text { suas regras de uso } \\
\text { dos recursos de } \\
\text { acesso comum ao } \\
\text { longo do tempo. }\end{array}$ & $\begin{array}{c}\text { Aquelas regras } \\
\text { definidas pela gestão } \\
\text { das áreas protegidas } \\
\text { não podem ser } \\
\text { modificadas nesta } \\
\text { categoria de unidade } \\
\text { de conservação. }\end{array}$ & $\begin{array}{l}\text { Inicialmente, pelo } \\
\text { Projeto Água Limpa, } \\
\text { as famílias eram } \\
\text { responsáveis por pagar } \\
\text { pela manutenção do } \\
\text { abastacimento de } \\
\text { água. Posteriormente } \\
\text { estas regras foram } \\
\text { modificadas em } \\
\text { função da participação } \\
\text { da Prefeitura } \\
\text { Municipal. }\end{array}$ & $\begin{array}{c}\text { Aquelas regras } \\
\text { definidas pela gestão } \\
\text { das áreas protegidas } \\
\text { não podem ser } \\
\text { modificadas nesta } \\
\text { categoria de unidade } \\
\text { de conservação. }\end{array}$ & $\begin{array}{l}\text { Inicialmente, pelo } \\
\text { Projeto Água Limpa, } \\
\text { as famílias eram } \\
\text { responsáveis por pagar } \\
\text { pela manutenção do } \\
\text { abastecimento de } \\
\text { água. Posteriormente } \\
\text { estas regras foram } \\
\text { modificadas em } \\
\text { função da participação } \\
\text { da Prefeitura } \\
\text { Municipal. }\end{array}$ \\
\hline $\begin{array}{c}\text { Infrações às regras } \\
\text { estabelecidas } \\
\text { para o uso dos } \\
\text { recursos de acesso } \\
\text { comum devem ser } \\
\text { monitoradas. }\end{array}$ & $\begin{array}{c}\text { As infrações são } \\
\text { monitoradas pela } \\
\text { fiscalização da Polícia } \\
\text { Militar Ambiental, } \\
\text { pelos vigilantes do } \\
\text { Pesm do Núcleo } \\
\text { Itutinga Pilões e pela } \\
\text { Prefeitura Municipal. } \\
\text { Recentemente } \\
\text { houve um reforço } \\
\text { na fiscalização militar } \\
\text { ambiental. }\end{array}$ & $\begin{array}{l}\text { Sem fiscalização } \\
\text { pelos participantes da } \\
\text { comunidade. Há regras } \\
\text { de uso definidas no } \\
\text { Projeto Água Limpa, } \\
\text { mas verifica-se que há } \\
\text { "gatos"na tubulação } \\
\text { que fornece água às } \\
\text { casas. }\end{array}$ & $\begin{array}{c}\text { As infrações são } \\
\text { monitoradas pela } \\
\text { fiscalização da Polícia } \\
\text { Militar Ambiental, } \\
\text { pelos vigilantes do } \\
\text { Pesm do Núcleo } \\
\text { Itutinga Pilões e pela } \\
\text { Prefeitura Municipal. } \\
\text { Recentemente } \\
\text { houve um reforço } \\
\text { na fiscalização militar } \\
\text { ambiental. }\end{array}$ & $\begin{array}{l}\text { Sem fiscalização pelos } \\
\text { participantes. Pela } \\
\text { proximidade com } \\
\text { o Núcleo Itutinga } \\
\text { Pilões, algumas } \\
\text { regras de construção } \\
\text { de fossas sépticas } \\
\text { foram definidas pela } \\
\text { comunidade em } \\
\text { parceria com o gestor } \\
\text { do parque. Há regras } \\
\text { de uso definidas no } \\
\text { Projeto Água Limpa, } \\
\text { mas verifica-se que há } \\
\text { "gatos"na tubulação } \\
\text { que fornece água às } \\
\text { casas. }\end{array}$ \\
\hline $\begin{array}{c}\text { Existência de um } \\
\text { sistema de sanções } \\
\text { graduais, de acordo } \\
\text { com o tipo de } \\
\text { infração às regras. }\end{array}$ & $\begin{array}{l}\text { Sanção de acordo com } \\
\text { o tipo de penalidade } \\
\text { instituído pelos órgãos } \\
\text { de fiscalização (Polícia } \\
\text { Militar e vigilantes } \\
\text { do Pesm) e pela } \\
\text { Prefeitura. }\end{array}$ & $\begin{array}{l}\text { Não possuem um } \\
\text { sistema de sanções } \\
\text { graduais para as } \\
\text { irregularidades. }\end{array}$ & $\begin{array}{l}\text { Sanção de acordo com } \\
\text { o tipo de penalidade } \\
\text { instituído pelos órgãos } \\
\text { de fiscalização (Polícia } \\
\text { Militar Ambiental e } \\
\text { fiscais do Pesm) e } \\
\text { pela Prefeitura. }\end{array}$ & $\begin{array}{l}\text { Não possuem um } \\
\text { sistema de sanções } \\
\text { graduais para as } \\
\text { irregularidades. }\end{array}$ \\
\hline $\begin{array}{c}\text { Existência de } \\
\text { mecanismos para a } \\
\text { solução de conflitos } \\
\text { no uso dos recursos } \\
\text { de acesso comum. }\end{array}$ & $\begin{array}{c}\text { Existência de } \\
\text { diferentes instâncias: } \\
\text { Conselho Consultivo } \\
\text { do Núcleo, vigilantes } \\
\text { do Pesm, gestor do } \\
\text { Núcleo Itutinga Pilões, } \\
\text { CDHU, vereadores e } \\
\text { Prefeitura Municipal. }\end{array}$ & $\begin{array}{c}\text { Núcleo mais isolado, } \\
\text { tende a não participar } \\
\text { dos processos e } \\
\text { programas. Estão se } \\
\text { organizando para } \\
\text { impedir sua saída sem } \\
\text { a devida indenização, } \\
\text { indo ao DER pedir um } \\
\text { atestado. }\end{array}$ & $\begin{array}{c}\text { Existência de } \\
\text { diferentes instâncias: } \\
\text { Conselho Consultivo } \\
\text { do Núcleo, vigilantes } \\
\text { do Pesm, gestor do } \\
\text { Núcleo Itutinga Pilões, } \\
\text { CDHU, vereadores e } \\
\text { Prefeitura Municipal. }\end{array}$ & $\begin{array}{c}\text { Estão procurando } \\
\text { advogados para } \\
\text { contratarem } \\
\text { conjuntamente } \\
\text { para defenderem } \\
\text { seus interesses de } \\
\text { permanecerem no } \\
\text { núcleo. }\end{array}$ \\
\hline
\end{tabular}




\begin{tabular}{|c|c|c|c|c|}
\hline Princípios & $\begin{array}{c}\text { Cota } 400 \text { - Regras } \\
\text { Formais }\end{array}$ & $\begin{array}{c}\text { Cota } 400 \text { - Regras } \\
\text { Informais }\end{array}$ & $\begin{array}{c}\text { Água Fria - Regras } \\
\text { Formais }\end{array}$ & $\begin{array}{c}\text { Água Fria - Regras } \\
\text { Informais }\end{array}$ \\
\hline $\begin{array}{c}\text { Reconhecimento } \\
\text { mínimo de direitos } \\
\text { para organização e } \\
\text { de estabelecimento } \\
\text { de regras próprias } \\
\text { no uso de acesso } \\
\text { comum. }\end{array}$ & $\begin{array}{c}\text { Só há reconhecimento } \\
\text { para as regras } \\
\text { congruentes com as } \\
\text { do Pesm. }\end{array}$ & $\begin{array}{c}\text { Organizam-se } \\
\text { para questionar } \\
\text { as propostas do } \\
\text { governo no Programa } \\
\text { de Recuperação } \\
\text { Socioambiental } \\
\text { da Serra do Mar. } \\
\text { Organizam-se } \\
\text { como Sociedade de } \\
\text { Melhoramentos da } \\
\text { Costa } 400 .\end{array}$ & $\begin{array}{c}\text { Só há reconhecimento } \\
\text { para as regras } \\
\text { congruentes com as } \\
\text { do Pesm. }\end{array}$ & $\begin{array}{c}\text { Organizam-se } \\
\text { para questionar } \\
\text { as propostas do } \\
\text { governo no Programa } \\
\text { de Recuperação } \\
\text { Socioambiental } \\
\text { da Serra do Mar. } \\
\text { Organizam-se } \\
\text { como Sociedade de } \\
\text { Melhoramentos da } \\
\text { Água Fria }\end{array}$ \\
\hline $\begin{array}{c}\text { Existência de } \\
\text { empreendimentos } \\
\text { inter-relacionados, } \\
\text { quando se tratar de } \\
\text { um grande sistema. }\end{array}$ & Não se aplica. & Não se aplica. & Não se aplica. & Não se aplica. \\
\hline
\end{tabular}

Fonte: Elaboração própria.

Quando se trata de obter acesso a um serviço básico, ou mesmo se organizar contra o Governo do Estado, o grupo se reúne, faz suas regras por seus interesses. Mesmo sem uma liderança real, a luta pelo inimigo comum pode uni-los, estabelecendo normas próprias. Um exemplo é a manutenção das casas "testemunhos" na Cota 400.

É neste contexto de atendimento às necessidades próprias que o formal e o informal se contrapõem. As comunidades sabem das regras de não desmatar, mas o farão se for necessário para um "puxadinho" para o irmão ou para o filho. Sabem que moram irregularmente num parque, mas não tinham outra opção.

A aproximação do formal com o informal será possível com a existência de mecanismos de fiscalização que sejam acompanhados do empoderamento da comunidade, com instrumentos participativos e com a presença de lideranças governamentais que não os vejam apenas como invasores, mas que os fomentem a atuar da melhor maneira possível para a preservação daquela área e daquele remanescente florestal. O perfil e o interesse da comunidade em conservar os recursos naturais também são necessários.

Entretanto, é difícil conter variáveis externas que fomentam a vinda de novas famílias sem o perfil e o interesse de conservação dos recursos de acesso comum nesta localidade. Com a atração de mão de obra para a indústria de Cubatão, principalmente de empreiteiras que não dão condições mínimas aos seus funcionários, há continuidade das invasões, do adensamento populacional e da exclusão social.

Verifica-se, também, que a política ambiental possui mecanismos importantes para promover o uso sustentável dos recursos naturais: a proximidade e a realização de trabalhos conjuntos; a existência de mecanismos de fiscalização, não apenas como um instrumento punitivo, mas preventivo; e a criação de instância de discussão e disseminação de informação. Com isso, as comunidades podem ser estimuladas a se organizarem e a estabelecerem suas regras de convívio e uso dos recursos naturais, seguindo os princípios elencados por Ostrom. 
Considerando os princípios que favorecem a ação coletiva aplicados a Água Fria e Cota 400, a seguir é apresentada a análise da performance institucional, tendo por base o modelo de Elinor Ostrom. De acordo com a análise do quadro 1, para cada princípio há uma classificação em Sim, Fraco, Médio ou Não, incluindo as regras formais e informais, resultando no quadro 2.

Quadro 2

Análise da performance institucional da Cota 400 e Água Fria

\begin{tabular}{|c|c|c|}
\hline Princípios & Cota 400 & Água Fria \\
\hline $\begin{array}{c}\text { Fronteira da comunidade para o uso } \\
\text { dos recursos de acesso comum deve } \\
\text { ser clara, com limites bem definidos e } \\
\text { com critérios para o ingresso de grupos } \\
\text { de usuários. }\end{array}$ & Fraco & Fraco \\
\hline $\begin{array}{l}\text { Regras de uso dos recursos de acesso } \\
\text { comum devem ser claras e bem } \\
\text { definidas, condicionadas à realidade } \\
\text { local. }\end{array}$ & Sim & Sim \\
\hline $\begin{array}{l}\text { Usuários devem ter o direito de } \\
\text { modificar suas regras de uso dos } \\
\text { recursos de acesso comum ao longo } \\
\text { do tempo. }\end{array}$ & Médio & Médio \\
\hline $\begin{array}{l}\text { Infrações às regras estabelecidas para } \\
\text { o uso dos recursos de acesso comum } \\
\text { devem ser monitoradas. }\end{array}$ & Médio & Médio \\
\hline $\begin{array}{l}\text { Existência de um sistema de sanções } \\
\text { graduais, de acordo com o tipo de } \\
\text { infração às regras. }\end{array}$ & Médio & Médio \\
\hline $\begin{array}{l}\text { Existência de mecanismos para a } \\
\text { solução de conflitos no uso dos } \\
\text { recursos de acesso comum. }\end{array}$ & Fraco & Fraco \\
\hline $\begin{array}{l}\text { Reconhecimento mínimo de } \\
\text { direitos para a organização e de } \\
\text { estabelecimento de regras próprias no } \\
\text { uso de acesso comum. }\end{array}$ & Médio & Médio \\
\hline $\begin{array}{l}\text { Existência de empreendimentos inter- } \\
\text {-relacionados, quando se tratar de um } \\
\text { grande sistema. }\end{array}$ & Não se aplica & Não se aplica \\
\hline Performance Institucional & Frágil & Frágil \\
\hline
\end{tabular}

Fonte: Elaboração própria. 
A partir da análise dos princípios verifica-se que a performance institucional dos dois casos demonstra ser frágil. Os mecanismos de fiscalização são robustos, as leis são claras e a prática demonstra insuficiência de organização e atuação efetiva da comunidade no uso sustentável dos recursos naturais, conforme proposto por Ostrom.

\section{Considerações finais}

A análise das características dos atores, da cultura, do ambiente socioeconômico e político do local e das práticas individuais e coletivas permite verificar que as regras formais foram os mecanismos que melhor condicionaram ou alteraram o uso dos recursos de acesso comum, sendo os arranjos da política ambiental instituições relativamente robustas. Nessas condições, a fiscalização e as regras formais do Pesm demonstram ser mecanismos importantes para alterar o comportamento e um meio para conservação dos recursos de acesso comum.

Nota-se que os indivíduos regram determinados comportamentos com a existência dos limites estabelecidos pelo Pesm. E os atores demonstram se importar com os recursos de acesso comum, mas colocam como primeira opção sua moradia e de outros familiares que possam vir a morar junto.

Ainda assim são verificadas características da comunidade que permitiram que a situação não ficasse pior. Quando são estimulados, atenderam às propostas de gestores de parques, como relatado na Água Fria. Em alguns momentos, faziam denúncias de novas invasões, buscavam mecanismos de impedir novas ocupações, apresentando características coerentes com a teoria de Ostrom.

Mas o interesse individual se sobrepõe ao da comunidade e da conservação dos recursos de acesso comum. A história de vida e as regras informais estabelecidas pela cultura nesses núcleos são fatores que contribuíram pouco para o desenvolvimento de instituições robustas para a proteção dos recursos de acesso comum, diferentemente de outras áreas, como de algumas comunidades em Ubatuba, onde sua cultura tradicional, a princípio, demonstra possibilidade de organização para conservação de recursos naturais.

Observa-se que as regras inerentes do Parque Estadual da Serra do Mar, por ser uma unidade de conservação de proteção integral, onde não é permitido o uso dos recursos naturais, contribuíram para conter um maior adensamento populacional com a atuação de gestores do Instituto Florestal. A ausência de uma fiscalização mais efetiva e de mecanismos de empoderamento da população não impediram novas invasões ao longo das décadas. Com a ampliação da fiscalização e do controle a partir de 2007, verificou-se uma redução do desmatamento nessas áreas, com demolições das novas invasões e dos "puxadinhos".

Mas apenas a existência da fiscalização não é um mecanismo suficiente para conter desmatamento e novas ocupações. A população precisa ser envolvida no processo de conservação dos recursos naturais.

Para o uso sustentável dos recursos comuns seria necessária a instituição de instrumentos de empoderamento da comunidade, estimulando sua participação e atuação, associada a mecanismos de direcionamento, regulação e ativismo por parte de órgãos públicos, com um mínimo de fiscalização. 
Nestes casos estudados, a teoria de Hardin demonstra prevalência, de modo que o controle estatal foi a melhor opção para conservação dos recursos naturais limitados, mas que demanda leis legítimas, como abordado pelo autor, pois aquelas apenas aplicadas por burocratas não foram suficientes. Um programa governamental mais amplo, de educação ambiental e realocação das famílias, considerando as características dos moradores nestas áreas, demonstra ser o meio para proteção dos remanescentes de Mata Atlântica do Parque da Serra do Mar.

\section{Referências}

BENJAMIN, Antonio. Direito ambiental das áreas protegidas: o regime jurídico das unidades de conservação. Rio de Janeiro: Forense Universitária, 2001.

BRASIL. Constituição da República Federativa do Brasil. Diário Oficial da União, Brasília, 5 out. 1988. N. 191-A.

BRASIL. Lei Federal no 7.804, de 18 de julho de 1989. Altera a Lei no 6.938, de 31 de agosto de 1981, que dispõe sobre a Política Nacional do Meio Ambiente, seus fins e mecanismos de formulação e aplicação, a Lei no 7.735, de 22 de fevereiro de 1989, a Lei no 6.803, de 2 de julho de 1980, e dá outras providências. Diário Oficial da União, Brasília, 19 jul. 1989.

BRASIL. Lei Federal no 9.985, de 18 de julho de 2000. Institui o Sistema Nacional de Unidades de Conservação. Diário Oficial da União, Brasília, 19 jul. 2000.

BRASIL. Lei Federal no 10.406, de 10 de janeiro de 2002. Institui o Código Civil. Diário Oficial da União, Brasília, 11 jan. 2002.

CDHU. Programa de Recuperação Socioambiental da Serra do Mar, município de Cubatão. Arrolamento e caracterização socioeconômica. São Paulo: Companhia de Desenvolvimento Habitacional e Urbano do Estado de São Paulo, 2007.

EHLERS, Eduardo M. Determinantes da recuperação da mata Atlântica no estado de São Paulo. Tese (doutorado) - Programa de Pós-Graduação em Ciência Ambiental, Universidade de São Paulo, São Paulo, 2003.

ESTADO DE SÃO PAULO. Constituição do Estado de São Paulo. Diário Oficial Estado de São Paulo, São Paulo, 5 out. 1989.

FENNY, David et al. A tragédia dos comuns: vinte e dois anos depois. In: DIEGUES, Antonio Carlos S.; MOREIRA, André de Castro C. (Org.). Espaços e recursos naturais de uso comum. São Paulo: Núcleo de Apoio à Pesquisa sobre Populações Humanas e Áreas Úmidas Brasileiras/USP, 2001. p. 17-42.

HARDIN, Garrett. Living within limits: ecology, economics and population taboos. Nova York: Oxford University Press, 1993.

HARDIN, Garrett. The tragedy of the commons. Science, v. 162, n. 3859, p. 1243-1248, 13 dec. 1963. 
MACHADO, Lucy M. C. P. Paisagem valorizada: a serra do Mar como espaço e como lugar. In: RIO, Vicente del; OLIVEIRA, Lívia de (Org.). Percepção ambiental: a experiência brasileira. São Paulo: Studio Nobel, 1996. p. 97-119.

MANKIW, Gregory N. Introdução à economia. Tradução de Allan Vidigal Hastings. São Paulo: Pioneira Thomson Learning, 2005.

McKEAN, Margaret A.; OSTROM, Elinor. Regimes de propriedade comum em florestas: somente uma relíquia do passado? In: DIEGUES, Antonio Carlos S.; MOREIRA, André de Castro C. (Org.). Espaços e recursos naturais de uso comum. São Paulo: Núcleo de Apoio à Pesquisa sobre Populações Humanas e Áreas Úmidas Brasileiras/USP, 2001. p. 79-95.

MORAN, Emilio F. Interações homem-ambiente em ecossistemas florestais: uma introdução. In: MORAN, Emilio; OSTROM, Elinor (Org.). Ecossistemas florestais: interação homem-ambiente. São Paulo: Editora Senac; Edusp, 2009. p. 19-40.

OST, François. A natureza à margem da lei: a ecologia à prova do direito. Tradução de Joana Chaves. Lisboa: Instituto Piaget, 1997.

OSTROM, Elinor. Governing the commons: the evolution of institutions for collective action. 21. ed. Nova York: Cambrige University Press, 2008.

OSTROM, Elinor. Understanding institutional diversity. Nova Jersey: Princeton University Press, 2005.

OSTROM, Elinor; TUCKER, Catherine. Pesquisa multidisciplinar relacionando instituições e transformações florestais. In: MORAN, Emilio; OSTROM, Elinor (Org.). Ecossistemas florestais: interação homem-ambiente. São Paulo: Editora Senac; Edusp, 2009. p. 109-138.

POLÍCIA MILITAR AMBIENTAL. Autuações bairros-Cota e Água Fria. São Paulo, 2010. Documento Interno.

PROJETO ÁGUA LIMPA. Projeto Água Limpa. Disponível em: <www.projetoagualimpa.net>. Acesso em: 5 jan. 2010.

SABBAGH, Roberta Buendia Sabbagh. Governo os comuns ou para os comuns? Gestão de áreas protegidas e os arranjos institucionais da política ambiental no Estado de São Paulo. Dissertação (Mestrado) — Fundação Getulio Vargas, São Paulo, 2010.

SÃO PAULO. Estado entrega 784 moradias do Programa de Recuperação da Serra do Mar. Disponível em: <www.sp.gov.br>. Acesso em: 12 jan. 2012.

SÃO PAULO. Plano de manejo do Parque Estadual da Serra do Mar. Governo do Estado de São Paulo, Secretaria de Estado do Meio Ambiente, Instituto Florestal, 2006.

SIMON, Hebert A. Rational decision making in business organizations. Pittsburgh: Carnegie-Mellon University, 1978.

Roberta Buendia Sabbagh é mestre em administração pública e governo pela Fundação Getulio Vargas de São Paulo (FGV-EAESP). E-mail: robertabs@gmail.com. 
